Chapter 4 has been published as:

Samsura, D.A.A. and van der Krabben, E. (2012)

NEGOTIATING LAND AND PROPERTY DEVELOPMENT: A GAME THEORETICAL APPROACH TO VALUE CAPTURING.

Journal of European Real Estate Research, 5(1), pp. 48-65 


\title{
4 NEGOTIATING LAND AND PROPERTY DEVELOPMENT: A GAME THEORETICAL APPROACH TO VALUE CAPTURING
}

\begin{abstract}
Purpose:

The results of the analysis attempt to provide an understanding on how a phenomenon or process of collective action with regard to in value capturing can be expected to happen in a certain way, which in the end it may contribute to the more successful implementation of value capturing.
\end{abstract}

\section{Design/methodology/approach:}

Game theory is utilized to model the structure of relations between the actors involved. Game theory is a mathematical approach to study collective decision-making situations in which the decision makers involved have conflicting preferences. Here, we consider the implementation of value capturing as the result of an agreement between a municipality and landowners to contribute to the costs of public infrastructure development which in essence is a form of collective action.

\section{Findings:}

The paper is not only demonstrating the usefulness of game theoretical modelling in conceptualising relations between different stakeholders in the implementation of value capturing and suggesting the best possible strategy for every stakeholder; but also observing the limitations of the methods in analyzing the behaviour of actors involved in decision-making processes with respect to value capturing.

\section{Originality:}

Unlike most of value capturing studies which focused on either a valuation point of view (how much value can be captured?), a governance or instrumentalist point of view (which instruments can be effective for value capturing?), or a political point of view (to whom belongs the increment value that is the result of government investments or decisions?); this paper emphasizes an alternative perspective, namely the decision-making or negotiation process of value capturing by relying on game-theoretical approach.

\subsection{Introduction: Public Infrastructure Financing and Value Capturing}

The financing of public infrastructure as a necessary condition for urban development projects has long been subject of many debates and discussions. Mainly, the problem has emerged as a result of the fact that governments have limited traditional sources of finance - which are 
mainly based on tax revenues - in providing and develop all desired infrastructures. With the increase of infrastructure scale and demand, there is a necessity for a greater collaboration between the public and private sector in infrastructure investment (Adair et al., 2011). In looking for alternatives extra funding for public infrastructure development, governments generally try to find a way that allows for efficient economic performance, financial justice, and social facility (Banister \& Berechman, 2000). Value capturing, to a certain extent, may offer an opportunity to achieve those goals (Batt, 2001; Doherty, 2004).

Value capturing can be defined as a process by which all or a portion of the increments in land and property value that resulted from the implementation of special public improvements, land use change or any other actions attributed to the public effort are recouped by the public sector and used for public purposes (Brown \& Smolka, 1997; Lari et al., 2009). A long tradition exists considering value capturing as a tool for public infrastructure investment. Meanwhile, many studies have been carried out with respect to value capturing (for instance, The RICS Policy Unit (2004) compiled a review of the literature on relation of public transport and land values). A substantial part of this literature is aimed at providing the empirical evidence of land and property value increases associated with the improvement of transportation infrastructure, especially rail transit, and the associated increased accessibility of the location (see e.g: Al-Mosaind et al., 1993; Diaz, 1999; Ryan, 1999). And yet in practice, the method is still not easy to be implemented. There are only few sources that explain the decision making process with respect to the implementation of value capturing. This could lead to the question whether value capturing might be a feasible method to co-finance infrastructure development.

One of the difficulties in implementing value capturing is related to the technique to determine the exact amount of increment value of land and properties directly resulting from the future improvement of the infrastructure service level. But perhaps the more imperative difficulties arise from the fact that value capturing, like any other common alternative resources of public funding, usually involves the introduction of fiscal interventions such as taxes, fees, exactions and charges (see e.g. Higginson, 1999; Batt, 2001; Gihring, 2001). The introduction of new fiscal programs may often be received with great scepticism from the public. Moreover, proposals for this kind of fiscal innovations often lack sufficient political support. As a result, land and property owners in many countries have a legal right to enjoy the (major part of the) increment value of their land and properties without any obligation to return it to the public, as for instance is the case in the Netherlands (Gielen, 2008). ${ }^{19}$ Consequently, the decision of the land and property owners to contribute to the financing of infrastructure development by giving up (part of) the increment value becomes dependent upon the profitability of such a decision for them. In addition to that, such a decision also entails interdependency between the private and public stakeholders that are involved in the implementation process of value capturing. An attempt to understand this interdependency and the way it can be organised and influenced might therefore be the key to a more successful implementation of value capturing, and conceivably, public-private financing of infrastructure development in general. 
In this paper, we offer a theoretical exploration of the interaction and interdependency among actors involved in the implementation of value capturing, by relying on concepts and approaches drawn from game theory. The objective of the paper is therefore - apart from improving our understanding of interdependency of main stakeholders in value capturing - to investigate the usefulness as well as the limitations of game theoretical modelling for analyzing the behaviour of actors involved in decision-making processes with respect to land and property development in general and the implementation of value capturing in particular. Game theory will be utilized to conceptualise the structure of relations between the actors involved, which in the end may lead us to a better insight into the plausibility of value capturing strategies.

The structure of this paper is as follows. Section 4.2 provides an introduction to game theory and a discussion of the supposed advantages of game theory analysis especially related to this study. In section 4.3, we develop some hypothetical cases of value capturing implementation and construct game theoretical models to analyse them. Section 4.4 presents a discussion about the results of the game theoretical analysis and the usefulness of game theory for modelling the implementation of value capturing. Finally, section 4.5 provides some conclusions and suggests steps for further research.

\subsection{Game-Theoretical Modelling}

Game theory is a mathematical approach to study social interactions (Myerson, 1991). It focuses on collective decision-making situations in which the decision makers involved have conflicting preferences. Its focus on the conflicting preferences has became the reason for some experts to describe game theory as a conflict theory (Luce \& Raiffa, 1957; Myerson, 1991). Aumann (1989) even proposes to speak of Interactive Decision Theory instead of Game Theory, since the former definition more accurately describes the content of the theory.

The interdependency of conflicting decision-making behaviour is an important element in game theory. This interdependency makes that the outcome of a game cannot be determined by only one actor. Thus, the outcome must be considered as a collective decision. Consequently, each actor tries to examine what strategies the other actors could perform and will adjust his or her own choice of action based on the expected actions of the others. Only by doing this, an actor can optimize his or her expected value of the outcome or, in game theoretical term, the payoff.

Another important element in game theory is the notion of rationality of individual decision makers, which means that they always try to maximize their expected utilities. To model rational individual decision making, Von Neumann \& Morgenstern, in their seminal book (1944), formulated the so-called expected utility theory which essentially is a theory of individual structures of satisfaction related to a particular outcome produced by a certain decision. In the further development of game theory, the concept of payoff has been introduced instead of expected utility. With this notion of rationality, game theory provides a simulation of individual's interest-based behaviour which often results in what is known as a non-cooperative situation, or a situation in 
which players compete and make decisions independently although their strategies and the outcomes of those strategies are interdependent to one another. ${ }^{20}$

As a model, a game is an abstraction of a real decision making situation. To construct a game, there are at least three aspects that must be defined (Colman, 1999), including:

- players

- strategies

- payoffs

The players in a game are the decision makers. A player is a primitive term and can only receive a meaning in an empirical setting. In this study, players are interpreted as actors involved in the implementation of value capturing in land and property development. A player is assumed as a unitary actor that makes decisions as if it is one single decision body (i.e. the municipality or the transport company can be considered as a players).

A strategy is a complete plan of actions which defines what a player might do in any given situation during the game (Colman, 1999). There is a similarity between a strategy in game theoretical terms and the business meaning of strategy. The strategic management literature contains a variety of definitions of the strategy concept, but most definitions have in common that a strategy contains long-term goals and objectives, as well as a plan of how to attain them (see e.g. Barney, 2002). In game theory, players also aim at a goal, namely utility maximization, and adopt a plan of how to reach this in their strategy. All players make their own choices by selecting a strategy, but the result for each player is partly dependent on the choice of the other player. This gives a strong notion of interdependency in game theory.

The third element in game theory is payoff. A payoff can be defined as the numbers associated with each possible outcome resulting from a complete set of strategic selections by all the players in a game (Colman, 1999). Higher payoff numbers are attached to outcomes that are valued higher in a player's rating system. The main assumption in game theory is that each player attempts to achieve as high a payoff for him or herself as possible in a game. It is important to make a clear distinction between the concepts of outcome and payoff. An outcome is a social or physical state which may result from the behaviour by individuals in the game. In fact, it is the decision, if any, arrived at by the players collectively. The payoff of an outcome for a player is the value of that outcome for the player. Different players will, in general, value outcomes differently. Usually, it is assumed in game theory that these outcome values are measured at the interval level (by means of expected utility functions). Clearly, it is here where conflict is brought in into the game. Players will have different valuation systems over the set of possible outcomes and hence different preferences over the outcomes. The individual payoff functions that assign values to outcomes vary across individuals. What the best outcome is for one player may be the worst for the other. The basic question therefore is how to solve games given these different payoff functions.

${ }^{20}$ Game theory can be distinguished into cooperative and non-cooperative. A game is called cooperative when players can make binding agreements and non-cooperative when there is no possibility of doing so. Cooperative games mainly deal with the situation in which groups or coalitions of players make decision together and involves the allocation of benefits from cooperation. The basic idea in cooperative games is that each player can gain more payoffs, i.e. arrive at a better outcome, by forming or joining a coalition. 
The most simple and common way to represent those three elements especially in noncooperative game, is to use a strategy form with a matrix that contains payoffs for any possible strategies for every player. In this matrix, the interdependent character of the players' interaction is manifest.

The construction of a game based on those three elements in the form of payoff matrix attempts to describe the strategic situation under scrutiny. It is however only one part of game theory. The other part is to investigate and predict the outcomes given the description of the game. The most eminent solution concept for games is the Nash Equilibrium. Technically, a Nash equilibrium can be defined as a profile of players' strategies such that no player individually has the incentive to deviate from its strategy, given that the other players adhere to their strategy (Osborne, 2004). A Nash equilibrium may therefore be seen as the outcome that is based on the best strategy that every player can take in a game. In principal, the theory of strategic games concentrates upon the existence of Nash equilibrium and/or on its refinements. It is possible however that a game may contain more than one Nash equilibrium or, even, no equilibrium. In the case when a game contains multiple equilibriums, a player can vary his use of strategies instead of choosing one strategy, hence, creating a mixed strategy.

\subsection{Game-Theoretical Analysis of Value Capturing: A Conceptual Approach}

In this section we consider land and property development processes in which a contribution of the landowner to the costs of public investments in infrastructure is negotiated between the municipality and the landowner. Concerning the analysis of value capturing strategies, a game theoretical approach might offer some advantages. First, it can be used to study stakeholders' interactions and their inter-related decision behaviour in the implementation of value capturing. The game might give an insight into how stakeholders behave strategically in deciding how to achieve the best outcome. Secondly, the implementation of value capturing, in essence, is the result of an agreement among several stakeholders to contribute to the costs of public infrastructure development. Both forming and managing an agreement is the result of collective actions. Focusing on collective actions, game theory is well-suited to study the implementation of value capturing. Moreover, game theory is not only suitable to describe collective actions but also to explain how collective actions work (Aumann, 1985). The explanations may provide an understanding of how a phenomenon or process of collective action with regard to value capturing can be expected to take place in a certain way.

From an analytical perspective, the main concern of this section is to provide a theoretical illustration of a game theory application to analyse the possibilities of value capturing assuming that the stakeholders involved act on their self-interest. In this situation, although each stakeholder makes a decision independently, the outcome of the stakeholders' actions cannot be decided individually and it depends on the particular actions or decisions taken by all stakeholders together. Consequently, each stakeholder has to take into account the expectation of what the others are doing in making his or her decision.

Regarding the increment value to be captured as a result of public infrastructure development, it is assumed to exist - in other words, there is a benefit to the landowner - and that 
there is no dispute about its exact amount. We would argue here that the discussion of value capturing implementation will not be brought to the table if the increment value is still unclear. Furthermore, in this illustration, it is assumed that both the location of the development and the parties involved are clear for all stakeholders, in order to avoid a boundary dispute over which party should be included or not in the value capturing. We assume that, for the municipality, the value that can be captured is 'substantial' (without it, the municipality will face substantial deficits in the budget). For the landowner, the contribution is also 'substantial' (however, the contribution will not bring him into insurmountable financial problems). Furthermore, we assume that no legislation exists that obliges landowners to contribute. The implementation processes of value capturing are expected to be the result of strategic decisions of both the public infrastructure developer (usually a government institution, e.g. municipality), with respect to the development of the infrastructure, and the landowner(s), with respect to the financial contribution to the necessary investments for the infrastructure development. Hence, the game-theoretical analyses aim at modelling the decisionmaking processes of both parties.

To analyse the implementation of value capturing, first we consider two different hypothetical situations, first with two players - the municipality and a landowner - as a basic model of the analysis and second with three players by adding one more landowner to the game, representing the more complicated situations with multiple players, which are often called n-person games. In these games, the municipality $(\mathrm{M})$ is the increment value creator and the landowner $(\mathrm{L})$ is the increment value receiver. Suppose the development of infrastructure will increase the value of land and property by a rate of $\rho$. It means that if the land has a total initial value of $x$, the development of the infrastructure will give the landowner an additional value of $\rho x$ which then creates a total value or payoff of $x+\rho x$ or $x(1+\rho)$ for the landowner. There are two strategies available to the landowner, which are to contribute and not contribute to the infrastructure development. At the same time, the municipality also has two options: to build and not build the infrastructure. Value capturing is implemented if only if the landowner agrees to give the increment value $\rho x$ to the municipality as a contribution to the infrastructure development when the municipality decides to build the infrastructure. Let's now consider two different situations in which value capturing might take place:

(a) The municipality cannot build the infrastructure if the landowner does not agree to give the increment value $\rho x$ as a contribution to the development.

(b) The municipality will build the infrastructure without the contribution from the landowner, but it still expects the contribution afterwards.

Two game-theoretical models using a payoff matrix can be constructed for the two situations (Fig. 4.1 and 4.2).

\begin{tabular}{lll|l|}
\multicolumn{3}{c}{} & \multicolumn{2}{c}{ Municipality } \\
\multirow{3}{*}{$\begin{array}{l}\text { Land- } \\
\text { owner }\end{array}$} & Contribute & Not build \\
\cline { 2 - 3 } & Not contribute & $x, \rho x$ & $x, 0$ \\
\cline { 2 - 3 } & $x, 0$ & $x, 0$ \\
\hline
\end{tabular}

Fig. 4.1 Two-person value capturing game for situation (a) 


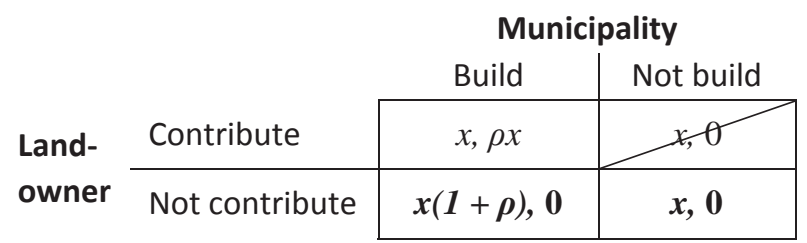

Fig. 4.2 Two-person value capturing game for situation (b)

In both models, the \{contribute, not build\} strategy is removed because it is very unlikely for the landowner to give a contribution when the municipality decides not to build or develop the infrastructure. In situation (a), the \{not contribute, build\} strategy is also removed because here the municipality cannot build the infrastructure without a contribution from the landowner.

As discussed earlier, the Nash equilibrium for those games can be identified by investigating each player's best response strategy. In (a), the Nash equilibrium can be found in two strategies: \{contribute, build\} and \{not contribute, not build\}. Since value capturing can be expected to take place in the \{contribute, build\} strategy, it means that value capturing is plausible in this situation. As the game has however two equilibriums, this situation suggests that value capturing is not the only best strategic behaviour to choose by the players involved.

Two Nash equilibriums are also found in (b) but not completely in the same pair of strategies as in (a). Here, the Nash equilibriums are found in the \{not contribute, build\} and \{not contribute, not build\}strategies. It means that value capturing is implausible to take place in this situation, because the strategy that suggests it is not the best strategic behaviour for the players to choose.

To complicate the situation, games for situations with three players can also be constructed as a basic model of a multiple player game for value capturing. In these 3-person games, an additional landowner is introduced to the model, which is denoted as Landowner 2. This player performs a similar strategy as the other landowner who was introduced earlier and here denoted as Landowner 1. Suppose the total initial values of Landowner 2's land and properties are denoted by $y$, the development of the infrastructure will thus give a total payoff of $y+\rho y$ or $y(1+\rho)$ to Landowner 2. With this additional player to the games, there are now eight pairs of strategies available in the game instead of the four that were found in the game with two players. The game-theoretical models of three players for both situation (a) and (b) are given in Fig. 4.3 and 4.4 respectively. As in the previous games, the strategies in which one landowner or both landowners contribute to the infrastructure development when the municipality decides not to build it, is removed from the game; as well as the strategies in which the municipality build the infrastructure while none of the landowners contributes. The latter is applied only in situation (a) where the municipality cannot build the infrastructure without a contribution from the landowner.

The Nash equilibrium of these two games are not all the same as in the games with two players. In situation (a), the Nash equilibrium is only found in the not contribute, not contribute, not build\} strategy which means that the strategy not to contribute to the infrastructure development is a pure strategy that should be chosen by all the landowners, while at the same time, it is best for the municipality not to build the infrastructure at all. This equilibrium shows that the implementation of value capturing is completely implausible in this situation. 


\begin{tabular}{|c|c|c|c|c|c|}
\hline & & & & & \\
\hline & & & & Build & Not build \\
\hline & & Land- & Contribute & $x, y, \rho(x+y)$ & $x, y, 0$ \\
\hline Land- & evtritsuce & 2 & $\begin{array}{c}\text { Not } \\
\text { contribute }\end{array}$ & $x, y(1+\rho), \rho x$ & \\
\hline 1 & & Land- & Contribute & $x(1+\rho), y, \rho y$ & \\
\hline & contribute & 2 & $\begin{array}{c}\text { Not } \\
\text { contribute }\end{array}$ & & $x, y, 0$ \\
\hline
\end{tabular}

Fig. 4.3 Three-person value capturing game for situation (a)

\begin{tabular}{|c|c|c|c|c|c|}
\hline & & & & Mu & \\
\hline & & & & Build & Not build \\
\hline & & Land- & Contribute & $x, y, \rho(x+y)$ & \\
\hline Land- & ectirisuce & 2 & $\begin{array}{l}\text { Not } \\
\text { contribute }\end{array}$ & $x, y(1+\rho), \rho x$ & \\
\hline 1 & Not & Land- & Contribute & $x(1+\rho), y, \rho y$ & \\
\hline & contribute & 2 & $\begin{array}{l}\text { Not } \\
\text { contribute }\end{array}$ & $x(1+\rho), y(1+\rho), 0$ & $x, y, 0$ \\
\hline
\end{tabular}

Fig. 4.4 Three-person value capturing game for situation (b)

In situation (b), there are two Nash equilibriums found which are not contribute, not contribute, build\} and \{not contribute, not contribute, not build\}. Similar to situation (a), value capturing in this situation is also implausible since the two equilibriums are found in a situation in which all the landowners should not contribute to the infrastructure development.

Value capturing seems to be implausible in almost all situations shown above because, with the simple structures used in our examples, it does not give a better payoff to the landowners. Hence, the game does not yield a Nash equilibrium that suggests value capturing. In order to adjust the Nash equilibrium towards the strategy that allows value capturing, two options can be taken into consideration. The first option is to increase the payoff for landowners when choosing contribute to such an extent that it exceeds the payoff for choosing not contribute. The other option is by lowering the payoff of choosing not contribute for the landowner so that it is below the payoff for choosing contribute. The first option can be achieved by offering or taking into account any additional incentives or benefits to a landowner for giving up the increment values to the municipality. The second option can be achieved by introducing a penalty or a fine to a landowner when he or she chooses not contribute, in the situation when the municipality decides to build the infrastructure. Afterwards, the value of the penalty should be given to the municipality as an additional payoff.

Let's now analyse the games for these two options. First is with the introduction of additional incentives for landowners when choosing contribute. Suppose the additional incentive to a landowner for contributing to the infrastructure development is denoted by $\pi$, then $\pi$ should be 
higher than the increment value created by the infrastructure development, i.e. $\pi>x(1+\rho)$ or $\pi>\rho x$ and $\pi>y(1+\rho)$ or $\pi>\rho y$. The payoff matrix for the games with two players for situation (a) and (b) are now given by Fig. 4.5 and Fig. 4.6 respectively, while Fig. 4.7 and 4.8 present the game with three players for respectively situation (a) and (b).

\begin{tabular}{ll|c|c|}
\multicolumn{2}{c}{} & \multicolumn{2}{c}{ Municipality } \\
\multirow{2}{*}{$\begin{array}{l}\text { Land- } \\
\text { owner }\end{array}$} & Contribute & Not build \\
\cline { 2 - 3 } & $x+\pi, \rho x$ & $x, 0$ \\
\hline & Not contribute & $x, 0$ & $x, 0$ \\
\cline { 2 - 3 }
\end{tabular}

Fig. 4.5 Two-person value capturing game with additional incentives for situation (a)

\begin{tabular}{ll|c|c|}
\multicolumn{2}{c}{} & \multicolumn{2}{c}{ Municipality } \\
\multirow{2}{*}{$\begin{array}{l}\text { Land- } \\
\text { owner }\end{array}$} & Contribute & Not build \\
\cline { 2 - 3 } & Not contribute & $x+\pi, \rho x$ & $x, 0$ \\
\cline { 2 - 3 } & $x(1+\rho), 0$ & $\boldsymbol{x}, \mathbf{0}$ \\
\hline
\end{tabular}

Fig. 4.6 Two-person value capturing game with additional incentives for situation (b)

\begin{tabular}{|c|c|c|c|c|c|}
\hline & & & & Mu & \\
\hline & & & & Build & Not build \\
\hline & & & Contribute & $x+\pi, y+\pi, \rho(x+y)$ & \\
\hline Land- & & 2 & $\begin{array}{l}\text { Not } \\
\text { contribute }\end{array}$ & $x+\pi, y(1+\rho), \rho x$ & \\
\hline 1 & Not & Land- & Contribute & $x(1+\rho), y+\pi, \rho y$ & $x, y, 0$ \\
\hline & contribute & 2 & $\begin{array}{l}\text { Not } \\
\text { contribute }\end{array}$ & & $x, y, 0$ \\
\hline
\end{tabular}

Fig. 4.7 Three-person value capturing game with additional incentives for situation (a)

\begin{tabular}{|c|c|c|c|c|c|}
\hline & & & & Mun & \\
\hline & & & & Build & Not build \\
\hline & & Land- & Contribute & $(x+\pi),(y+\pi), \rho(x+y)$ & \\
\hline Land- & - & 2 & $\begin{array}{l}\text { Not } \\
\text { contribute }\end{array}$ & $(x+\pi), y(1+\rho), \rho x$ & \\
\hline 1 & Not & Land- & Contribute & $x(1+\rho),(y+\pi), \rho y$ & \\
\hline & contribute & 2 & $\begin{array}{l}\text { Not } \\
\text { contribute }\end{array}$ & $x(1+\rho), y(1+\rho), 0$ & $x, y, 0$ \\
\hline
\end{tabular}

Fig. 4.8 Three-person value capturing game with additional incentives for situation (b) 
In games with two players, the change of the Nash equilibrium only takes place in situation (b) where the Nash equilibrium is now shifting from \{not contribute, build\} strategy to \{contribute, build\} strategy. It suggests that the implementation of value capturing is now plausible in this situation. Nevertheless, in both games, the Nash equilibrium is also found in the pair of strategy \{not contribute, not build\} which means that the solutions for these games are not a pure strategy since there is another strategy which can be considered as a best response for all players.

The same phenomenon also occurs in games with three players. In both games for situation (a) and (b), the Nash equilibrium are found in two pairs of strategies: \{contribute, contribute, build\} that suggests the implementation of value capturing with all landowners, and not contribute, not contribute, not build\} that suggests no implementation of value capturing at all and no infrastructure development.

Now let's analyse the games with the introduction of a penalty or a fine to landowners for choosing not contribute. Suppose the fine is denoted by $\varphi$ which is given as a certain proportion of the total value of land and properties affected by the infrastructure development. It means that if a landowner refuses to give a contribution to the development of the infrastructure, he or she will receive a payoff of $x(1+\rho)(1-\varphi)$, while at the same time the municipality will receive $\varphi x(1+\rho)$ as a payoff. In order to make sure that the landowner's payoff is higher when he or she contributes to the infrastructure development after the municipality decides to build it, the fine should satisfy $\varphi>1-\frac{1}{1+\rho}$.

By introducing a penalty to landowners for choosing not contribute after the municipality decides to build the infrastructure, the distinction between situation ( $a$ ) and (b) becomes irrelevant. Consequently, there is only one game constructed for two players and also one game for three players. These two games are given in Fig. 4.9 and 4.10 respectively.

\begin{tabular}{llc|c|}
\multicolumn{3}{c}{} & \multicolumn{2}{c}{$\begin{array}{c}\text { Municipality } \\
\text { Luild }\end{array}$} & Not build \\
\cline { 2 - 3 } Land- & \multicolumn{1}{c}{ Conner } & $\boldsymbol{x}, \boldsymbol{\rho} \boldsymbol{x}$ & $\boldsymbol{x}, \boldsymbol{0}$ \\
\cline { 2 - 3 } & Not contribute & $x(1+\rho)(1-\varphi), \varphi x(1+\rho)$ & $x, 0$ \\
\cline { 2 - 3 } & &
\end{tabular}

Fig. 4.9 Two-person value capturing games with penalty

\begin{tabular}{|c|c|c|c|c|c|}
\hline \multirow{3}{*}{\multicolumn{2}{|c|}{ Contribute }} & \multirow{4}{*}{$\begin{array}{l}\text { Land- } \\
\text { owner } \\
2\end{array}$} & & \multicolumn{2}{|l|}{ Municipality } \\
\hline & & & & Build & Not build \\
\hline & & & Contribute & $x, y, \rho(x+y)$ & \\
\hline \multirow{3}{*}{$\begin{array}{l}\text { Land- } \\
\text { owner } \\
1\end{array}$} & & & $\begin{array}{l}\text { Not } \\
\text { contribute }\end{array}$ & $x, y(1+\rho)(1-\varphi), \rho x+\varphi y(1+\rho)$ & \\
\hline & \multirow{2}{*}{$\begin{array}{l}\text { Not } \\
\text { contribute }\end{array}$} & \multirow{2}{*}{$\begin{array}{l}\text { Land- } \\
\text { owner } \\
2\end{array}$} & Contribute & $x(1+\rho)(1-\varphi), y, \varphi x(1+\rho)+\rho y$ & \\
\hline & & & $\begin{array}{l}\text { Not } \\
\text { contribute }\end{array}$ & $x(1+\rho)(1-\varphi), y(1+\rho)(1-\varphi), \varphi(x+y)(1+\rho)$ & $x, y, 0$ \\
\hline
\end{tabular}

Fig. 4.10 Three-person value capturing games with penalty 
There is only one Nash equilibrium found both in 2-person and 3-person games which gives the two games a pure strategy. In the 2-person game, this strategy is the pair \{contribute, build\}and in 3-person game, it is the \{contribute, contribute, build\} strategy. It means that the implementation of value capturing in these situations is naturally the only strategy for the stakeholders to choose. This result suggests that manipulation of the payoff structure might put forward the Nash equilibrium towards the desired solution.

\subsection{Discussion: Investigating the Applicability of Game Theory}

As demonstrated in the previous section, game-theoretical approaches can be used to analyse the implementation of value capturing and to contribute to our understanding of complex collective decision making. Nonetheless, the real world seems to be much more complex than the model abstraction in game theory as constructed in this paper. In this section, we therefore will discuss the validity of game-theoretical models we have introduced earlier by investigating how useful these models are to explain and understand about the reality of value capturing. In order to do so, first we will discuss about the specific (Dutch) institutional context within which value capturing is applied. This will include a brief discussion of the land development regime and value capturing mechanisms, specifically in the Netherlands. Secondly, we will discuss the results of the empirical testing of the models based on a survey among real estate professionals in the Netherlands, to observe how close the survey results are from what has been suggested by the game-theoretical models.

\subsubsection{Land Development and Value Capturing in the Netherlands}

Dutch municipalities have always felt responsible for the development of land and they have had high ambitions for the way in which they want their land to be used (Needham, 2007). For that reason, municipalities in the Netherlands frequently choose a public land development approach, also known as active land policy. With this approach, municipalities actively purchase all required land to be developed, readjust the parcels into building plots suitable for the desired development, service the land by providing necessary infrastructures and utilities, and after that release the parcels to builders/developers and occupiers (van der Krabben \& Needham, 2008). Supported by subsidies from the central government, this practice has not only made municipalities to be able to steer land development as they desire but also led to a public predominance in land development and serviced building plots supplies.

In the 1980s, the Netherlands encountered a hard economic recession that forced both local and national governments to cut their budgets which consequently has changed the role of municipalities in land development. Municipalities have turned their focus to a more passive role by relying on law instruments including land use plans and building permits, to control land development process. In contrast, private parties gradually have taken over the land market, specifically in land supply, especially since the rise of the housing market and increase in housing price in 1990s (Priemus \& Louw, 2003). Since then, municipalities have experienced several problems if they want to maintain their ambitions in land use, which are related to such aspects including property rights, economic interests of users and owners, and most importantly, the financing of public infrastructures and facilities (Verhage \& Needham, 2003; Louw, 2008). 
As land supplies are increasingly in private hands and subsidies from central government are decreasing, municipalities have to work out alternative ways to finance public infrastructure and utilities developments. Value capturing has been labelled as one of promising means to overcome this problem. In 2001 and also in 2004, the Dutch national government issued a memorandum on Land Policy which included a consideration to make (better) use of value capturing (VROM, 2001; 2004; RVW, 2004). However, the succeeding government had a negative attitude to it and until now there is no legal instrument in the Netherlands that specifically allows for value capturing. ${ }^{21}$ Conceivably, the reluctance to value capturing is derived from the fact that the general system in the Netherlands has considered that the value increase of land caused by any change of the admitted land use falls to the landowner, which means that landowners have a right to enjoy the increment value caused by public investments for themselves without any obligation to give it back to the public (de Wolff, 2007; Munoz Gielen, 2008).

In 2008, Dutch government introduced a new Spatial Planning Act (Wet ruimtelijke ordening) that enlarges the possibilities of public authorities to enforce private developer to contribute to public infrastructure investment. Based on this legislation, private parties can be forced - if they do not contribute voluntarily - to contribute to the financing of plan-related costs of public works. However, this regulation is limited to cost recovery even though the benefits that are received by the private parties as a result of the public infrastructure development may exceed the development costs.

\subsubsection{Possibility of value capturing: a survey on game theoretical-models}

Due to the lack of a specific legal instrument, it is essential (in the Dutch context) to understand the effects of a decision of the public authorities to implement value capturing on the behaviour of private actors and the consequences for the profitability of the investments by both parties. Game-theoretical models that are constructed in section 3 have provided some theoretical perspectives about the possibility of value capturing, by taking into account the interactions structure and the inter-related decision behaviour of stakeholders involved. In this section, we aim to compare the outcome of the models with similar games played by real actors. In order to do so, we have carried out an empirical testing of the models based on a survey among Dutch real estate professionals.

In this survey, we focused on the decision behaviour of landowners with respect to value capturing to observe their preferences in contributing to the financing of public infrastructure, by giving up the increment values (which are the result of that infrastructure). To illustrate their behaviour, we constructed a hypothetical situation where there is only municipality and landowner involved in value capturing. In this situation, the municipality is the increment value creator and the landowner is the increment value receiver. We refer to a study by Van der Krabben et al. (2008) that calculated the potential for value capturing in three Dutch station redevelopment projects, illustrating the amount of the increment value to be contributed by the landowner or captured by the municipality. The landowner has two strategies: to contribute or not to contribute the increment

21 Actually, municipalities do have a legal instrument for value capturing (baatbelasting or profit tax), but this instrument is never used because of serious legal problems (Munoz Gielen, 2008). 
value to the municipality for the infrastructure development. The municipality also has two options: to build the infrastructure and not to build the infrastructure. Given this hypothetical situation, the respondents were asked to reveal their preferences about their possible strategy by taking into consideration 10 different decision moments, associated with the games in Fig. 1 to Fig. 10 which have been constructed in section 3 . There are 39 professionals involved in this survey. The results of the survey are given in table 4.1 .

Table 4.1. The result of the survey

\begin{tabular}{|c|c|c|c|c|c|c|c|c|c|c|}
\hline & Game & Game & Game & Game & Game & Game & Game & Game & Game & Game \\
& 1 & 2 & 3 & 4 & 5 & 6 & 7 & 8 & 9 & 10 \\
\hline \# Contribute & 15 & 5 & 3 & 4 & 23 & 22 & 22 & 22 & 37 & 37 \\
$\%$ & 38,5 & 12,8 & 7,7 & 10,3 & 59,0 & 56,4 & 56,4 & 56,4 & 94,9 & 94,9 \\
\hline \# Not contribute & 24 & 34 & 36 & 35 & 16 & 17 & 17 & 17 & 2 & 2 \\
$\%$ & 61,5 & 87,2 & 92,3 & 89,7 & 41,0 & 43,6 & 43,6 & 43,6 & 5,1 & 5,1 \\
\hline
\end{tabular}

From the table, we can see that most of respondents prefer to choose to give no contribution in game 1 to 4 , which means that value capturing is not plausible in the corresponding situations. Recalling from section 3 , these results relatively resemble what has been suggested from the analyses for game-theoretical models as shown in Fig. 1 to Fig. 4. As discussed earlier, the model in Fig. 1 suggests that to contribute is not the only best strategic behaviour to choose by the landowner. With a result of $38,5 \%$ of the respondents willing to contribute and $61,5 \%$ against value capturing, it means that the difference between the two options is relatively close. The analyses for the models that are shown in Fig. 2 to Fig. 4 in section 3 suggest that value capturing is implausible to take place in the corresponding situations, because the option to contribute to the infrastructure development is definitely not the best strategic behaviour for the landowners. The results of the survey strongly confirm this with around $90 \%$ of respondents not in favour of value capturing in game 2 to 4.

From the survey we also found that for game 5 to 10, most of the respondents prefer to choose to contribute, which means that value capturing is plausible in the corresponding situations. Recalling from Section 3, these games are reflecting the situations in which the payoff structure is manipulated by two different kinds of interventions, namely by offering additional incentives or benefits to a landowner for giving up the increment values to the municipality (in game 5 to 8 ) and by introducing a penalty or a fine to landowners when they choose not to contribute (in game 9 and 10). As discussed in Section 3, although game 5 to 8 suggest that the implementation of value capturing is plausible in these corresponding situations, the strategy to contribute is not a pure strategy for landowners since not to contribute can also be considered as their best strategy. In the survey, we found for game 5 to 8 that the differences between the result of respondents who choose to contribute or not to contribute are very small with almost equal percentages, as shown in table 1. Meanwhile, the results of the survey for game 9 and 10 show that almost all respondents choose to contribute. This result confirms the analysis for the associated games in Section 3 that suggested a high possibility of value capturing since in the situations as described for these games, the decision to contribute is the only best strategy for the landowner. 
From the survey, we found that the results of the game-theoretical analyses are confirmed when the situations are countered by real actors. These results also confirm that game-theoretical approaches can be used to analyse the implementation of value capturing and to contribute to our understanding of complex collective decision making. Nonetheless, the real world seems to be much more complex than the model abstraction in game theory as constructed in this paper. One possible comment is that, in the case of the actual implementation of value capturing, this usually takes place in a dynamic settings instead of the static one as employed in this paper where the decisions are not taken simultaneously by all players but sequentially. Moreover, all game-theoretical models constructed above are based on non-cooperative approaches. Problems have been recognized from those models especially when the game consists of more than two players. In those situations, a non-cooperative game cannot take into account the increasing significance of coalition formation among players, which will bring a concern to things such as cooperation, organizational structure, compromise and threat.

Nevertheless, we believe that - as the next steps in the construction of the model - at least part of those complexities can be brought into the model. For instance, the dynamics of the situation when players are interacting in sequence setting can be modelled using games in extensive form (Samsura et al., 2010). Furthermore, to take account of the increasing significance of coalition formation among players especially when the situation involves multiple players, the game can be constructed with a cooperative approach using coalition form (Kahan \& Rapoport, 1984; Samsura \& Van der Krabben, 2011).

With respect to land and real estate development processes, the applications of game theory so far are limited in number (Berkman, 1965; Batty, 1977; Mu \& Ma, 2007). Nevertheless, since the issues of pluriformity, complexity and interdependency have increased in many land development process (Needham, 2007), we believe that game theory and game-theoretic modelling might offer a means that could lead to new and fruitful insights into the analysis of land and property development in particular and urban studies in general. Game theory is also well-suited to explain social dilemmas and collective actions in land development processes. The explanations will provide new motivations about why such phenomena or processes of collective action with regard to land and property development processes occurs in a certain way.

\subsection{Conclusion}

The concept of value capturing is often studied from either a valuation point of view (how much value can be captured?) (e.g. Benjamin \& Sirmans, 1996; Debrezion et al., 2007; Hess \& Almeida, 2007), from a governance or instrumentalist point of view (which instruments can be effective for value capturing?) (e.g. Batt, 2001; Gihring, 2001; van der Krabben \& Needham, 2008), or even from a political point of view (to whom belongs the increment value that is the result of government investments or decisions?) (e.g. Claydon \& Smith, 1997; Fordham, 1989; Gielen \& Tasan-Kok, 2010). The present paper emphasizes an alternative perspective to value capturing, namely the decision-making or negotiation process underlying value capturing. Depending on, among other things, the status of the legislation for legislation, the amount of value that can be captured and power relations between the stakeholders involved, value capturing is the outcome of a process of negotiations between stakeholders. For a better understanding of the decision-making process, the paper suggests modelling experiments and discusses the initial explorative concept of 
game-theoretical modelling. The analysis has focused on the stakeholders' strategic behaviour with respect to value capturing. By employing game-theoretical models, this paper has been demonstrated how this approach can be useful for such an analysis and can improve our understanding about collective decision making problems in the implementation of value capturing. The models offer a useful method to conceptualise relations between different stakeholders. Furthermore, by taking into account stakeholders' responses to each others' strategies, the solution of the game can be used to suggest the best possible strategy for every stakeholder.

\section{References}

Adair, A., Berry, J., Gulati, M., Haran, M., Hutchinson, N., Kasyap, A., McCord, M., McGreal, S., Oyedele, J., Tiwari, P. (2011). The Future of Private Finance Initiative and Public Private Partnership.

Al-Mosaind, M. A., Dueker, K., \& Strathman, J. G. (1993). Light-Rail Transit Stations and Property Values: A Hedonic Price Approach. Transportation Research Record, 1400, 90-94.

Aumann, R. J. (1985). What Is Game Theory Trying to Accomplish? In K. Arrow \& S. Honkapohja (Eds.), Frontiers of Economics. Oxford: Blackwell.

Aumann, R. J. (1989). Lectures on Game Theory. Boulder: Westview Press.

Aumann, R. J. (1997). Rationality and Bounded rationality. Games and economic behaviour, 22, 2-14.

Aumann, R. J., \& Mascheler, M. (1995). Repeated Games with incomplete information. Cambridge, MA: MIT Press.

Banister, D., \& Berechman, J. (2000). Transport Investment and Economic Development. London: UCL Press.

Barney, J. (2002). Gaining and sustaining competitive advantage. Upper Saddle River: Prentice Hall.

Batt, H. W. (2001). Value Capture as a Policy Tool in Transportation Economics: An Exploration in Public Finance in the Tradition of Henry George. American Journal of Economics and Sociology, 60(1), 195-228.

Batty, S. E. (1977). Game-theoretic approaches to urban planning and design. Environment and Planning B: Planning and Design, 4(2), 211-239.

Benjamin, J. D., \& Sirmans, G. S. (1996). Mass Transportation, Apartment Rent and Property Values. Journal of Real Estate Research, 12(1), 1-8.

Berkman, H. G. (1965). The Game Theory of Land Use Determination. Land Economics, 41(1), 11-19.

Brown, H. J., \& Smolka, M. O. (1997). Capturing Public Value from Public Investment. In H. J. Brown (Ed.), Land Use and Taxation: Applying the Insight of Henry George. Cambridge, MA: Lincoln Institute of Land Policy.

Camerer, C. (1991). Does strategy research need game theory? Strategic Management Journal, 12, 137-152.

Claydon, J., \& Smith, B. (1997). Negotiating Planning Gains through the British Development Control System. Urban Studies, 34(12), 2003-2021. 
Colman, A. (1999). Game Theory and its Applications: In the Social and Biological Sciences. London: Routledge.

Debrezion, G., Pels, E., \& Rietveld, P. (2007). The Impact of Railway Stations on Residential and Commercial Property Value: A Meta-analysis. The Journal of Real Estate Finance and Economics, 35(2), 161-180.

Diaz, R. B. (1999). Impacts Of Rail Transit On Property Values. Commuter Rail/Rapid Transit Conference (pp. 1-8). Toronto: American Public Transit Association.

Doherty, M. (2004). Funding public transport development through land value capture programs. Sydney.

Fordham, R. (1989). Planning gain: towards its codification. Journal of Planning and Environmental Law, August, 577-584.

Gibbons, R. (1992). Game Theory for Applied Economists. Princeton: Princeton University Press.

Gihring, T. (2001). Applying Value Capture in the Seattle Region. Planning Practice and Research, 16(3-4), 307-320.

Goeree, J., \& Holt, C. (2001). Ten little treasure of game theory and ten intuitive contradictions. American Economic Review, 91(5), 1401 - 1422.

Harsanyi, J. C. (1967). Games with Incomplete Information Played by "Bayesian" Players, I-III Part I. The Basic Model. Management Science, 14(3), 159-182.

Hess, D. B., \& Almeida, T. M. (2007). Impact of Proximity to Light Rail Rapid Transit on Station-area Property Values in Buffalo, New York. Urban Studies, 44(5), 1041-1068.

Higginson, M. (1999, September). Alternative Sources of Funding. Public Transport International 48.

Kahan, J. P., \& Rapoport, A. (1984). Theories of Coalition Formation. New York: Psychology Press.

van der Krabben, E., \& Needham, B. (2008). Land readjustment for value capturing: A new planning tool for urban development. Town Planning Review, 79(6), 651-672.

Lari, A., Levinson, D., Zhao, Z., Iacono, M., Aultman, S., Das, K. V., Junge, J., Larson, K., Scharenbroich, M. (2009). Value Capture for Transportation Finance: Technical Research Report. Center for Transportation Studies Report 0918. Minneapolis, MN.

Louw, E. (2008). Land assembly for urban transformation: The case of 's-Hertogenbosch in The Netherlands. Land Use Policy, 25(1) 69-80.

Luce, R. D., \& Raiffa, H. (1957). Games and Decisions. New York: Willey.

Mu, L., \& Ma, J. (2007). Game Theory Analysis of Price Decision in Real Estate Industry. International Journal of Nonlinear Science, 3(2), 155-160.

Munoz Gielen, D. (2008). Public Value Capturing and the Financing of Public Infrastructure in England, Valencia, and the Netherlands. In R. Alterman \& M. Gdesz (Eds.), The 2nd International Seminar on Planning, Law, and Property Rights. Warsaw: International Academic Association on planning, law and property rights. 
Munoz Gielen, D. \& Tasan-Kok, T. (2010). Flexibility in Planning and the Consequences for Publicvalue Capturing in UK, Spain and the Netherlands. European Planning Studies, 18(7), 1097-1131.

Myerson, R. B. (1988). Mechanism Design. Evanston, Illinois.

Myerson, R. B. (1991). Game Theory: Analysis of Conflict. Boston: Harvard University Press.

Needham, B. (2007). Dutch land use planning: Planning and managing land use in the Netherlands, the principles and the practice. The Hague: Sdu uitgevers.

Osborne, M. J. (2004). An Introduction to Game Theory. New York: Oxford University Press.

Plous, S. (1993). The Psychology of Judgment and decision Making. London: McGraw-Hill.

Poundstone, W. (1993). Prisoner's Dilemma: John Von Neumann, Game Theory and the Puzzle of the Bomb. New York: Doubleday.

Priemus, H. \& Louw, E. (2003). Changes in Dutch land policy: from monopoly towards competition in the building market. Environment and Planning B: Planning and Design, 30, 369-378.

RICS Policy Unit. (2004). Land Value and Public Transport: stage two - Summary and Findings. Coventry.

RVW (Raad voor Verkeer en Waterstaat) (2004). leder zijn deel: Locatiebereikbaarheid anders aanpakken

Ryan, S. (1999). Property Values and Transportation Facilities: Finding the Transportation-Land Use Connection. Journal of Planning Literature, 13(4), 412-427.

Samsura, D. A. A., van der Krabben, E., \& van Deemen, A. M. A. (2010). A game theory approach to the analysis of land and property development processes. Land Use Policy, 27(2), 564-578.

Samsura, D.A.A. and van der Krabben, E. (2011). Funding Transport Infrastructure Development through Value Capturing: A Game Theoretical Analysis. In van Nunen, Huijbregts, P. and Rietveld, P. (Eds.), Transitions Towards Sustainable Mobility: New Solutions and Approaches for Sustainable Transport Systems. (Berlin Heidelberg: Springer-Verlag,)

Simon, H. (1978). Rationality as process and product of thought. The American Economic Review, 68(2), 1-7.

Smith, J. J., \& Gihring, T. A. (2006). Financing Transit Systems Through Value Capture: An Annotated Bibliography. American Journal of Economics and Sociology, 65(3), 751-786.

Verhage, R. \& Needham, B. (2003), Financing Public Facilities in Housing Projects: a Method for Understanding Negotiating Processes. In Ennis, F. (ed) Infrastructure Provision and the Negotiating Process, Aldershot: Ashgate.

von Neumann, J., \& Morgenstern, O. (1944). Theory of Games and Economic Behaviour. Princeton: Princeton University Press.

VROM (Ministry for Housing, Planning and the Environment) (2001). Grond voor nieuw beleid - nota Grondbeleid (memorandum on land policy) 
VROM (Ministry for Housing, Planning and the Environment) (2004). Nota Ruimte. Ruimte voor ontwikkeling. The Hague 